\title{
The High Cost of Opioid Use in Pregnancy
}

\author{
Michael D. Jacobson ${ }^{1}$; Josephine Wilson ${ }^{2 i}$ Anna Squibb ${ }^{3}$; Lisa Collier Kellar ${ }^{1,4}$ \\ ${ }^{1}$ Department of Family Medicine, Boonshoft School of Medicine, Wright State University, Dayton, $\mathrm{OH}$ \\ ${ }^{2}$ Department of Population \& Public Health Sciences, Boonshoft School of Medicine, Wright State University, Dayton, $\mathrm{OH}$ \\ ${ }^{3}$ Department of Medical Education, Kettering Health Network, Dayton, $\mathrm{OH}$ \\ ${ }^{4}$ Department of OB/GYN, Boonshoft School of Medicine, Wright State University, Dayton, $\mathrm{OH}$ \\ Corresponding Author: Michael D. Jacobson, 4222 Tylersville Road, West Chester, OH 45011, (513) 403-3900, office@redemptiv.com \\ Submitted June 15, 2021 Accepted December 3, 2021 Published January 28, 2022 https://doi.org/10.18061/ojph.v4i2.8407
}

\section{ABSTRACT}

Background: Numerous investigators have highlighted the need to integrate opioid use disorder (OUD) treatment with maternity care. Since data first became available in 2014, Montgomery County (Ohio) has experienced the highest rates of OUD and unintended opioid overdose deaths in the state. This paper examines the demographics and costs of medical treatment for pregnant women with OUD and their newborns with prenatal exposure to opioids (PEO).

Methods: The study involved a retrospective records review of all newborns born between May 1, 2016, and April 30, 2017, at a large, urban medical center. Newborns with PEO were matched with a control group by mother's type of insurance, race/ethnicity, method of birth, and maternal parity.

Results: Establishing which of the pregnant women should be diagnosed with OUD and be included in the study group was inordinately challenging. Ultimately, of the 3841 infants birthed during the study period, 131 (3.4\%) were identified as being born to mothers with OUD. Significantly more mothers with OUD were White and on Medicaid. Only 25 (19.2\%) mothers with OUD engaged in treatment for substance use. Compared to the control group, newborns with PEO were much more likely (71.4\% versus $25.4 \%$ ) to be admitted to the NICU and had much longer lengths of stay in both the NICU (mean of 14.4 versus 4.1 days) and hospital (16.9 versus 5.8 days), resulting in dramatic increases in health care cost.

Conclusion: These data underscore the need for a comprehensive, systematic approach to OUD and PEO and affirm the government as a major stakeholder in the care of infants born to these women.

Keywords: Prenatal; Opioid; Ohio; Cost; Case control

\section{INTRODUCTION}

Since 2014 (when the Ohio Department of Health first published these data), Montgomery County (Ohio) has experienced the highest rates of OUD and unintended opioid overdose deaths in the state. $^{1-6}$ Nationally, between 1999 and 2014, the prevalence of maternal OUD more than quadrupled from 1999 (1.5 per 1000 hospital deliveries) to 2014 (6.5 per 1000). ${ }^{7}$ By 2017, the incidence had climbed to 8.2 per 1000 hospital deliveries, and 7.3 per 1000 newborns were diagnosed with neonatal abstinence syndrome (NAS). ${ }^{8}$ Furthermore, investigators have found that the prevalence of OUD in pregnant women is systematically underestimated. ${ }^{9}$ Numerous investigators have highlighted the critical need to integrate opioid use disorder (OUD) treatment with maternity care. ${ }^{10,11}$ Pregnancy complications such as fetal growth restriction, abruptio placentae, fetal death, and preterm labor are common with OUD. ${ }^{12}$ Additionally, untreated OUD has increased high-risk sexual activity, exposure to sexually transmitted infections, violence, and criminal activity. ${ }^{12}$ Many of the pregnancies complicated by OUD are often also found to be complicated by comorbid mental health conditions. ${ }^{12,13}$ Finally, the rates of follow up postpartum visits to assure the care of the couplet is substantially decreased for persons with substance use disorders. This affects evaluation, identification, and treatment of postpartum mood disorders and future rates of unintended pregnancy, specifically.12, 14 
Accurate diagnosis of OUD in persons receiving prenatal care is notably difficult. The American College of Obstetrics and Gynecology (ACOG) has provided recommendations for screening for OUD during prenatal care since 2012.15 However, issues surrounding OUD continue to abound, as evidenced in the updated ACOG guidelines from 2021, which includes stronger language and specific screening modalities. ${ }^{12}$ In Ohio, a volunteer survey of women who delivered in 2017 showed that of those receiving prenatal care, $82 \%$ were screened for substance use. ${ }^{16}$ However, the variable rates of appropriately timed prenatal care among persons with OUD who are pregnant is a noted challenge to improving care for this population. ${ }^{12}$ In addition, due to the lack of standardized practices for in-hospital treatment of infants born opioid-exposed, the cost of care and length of stay varies widely. Specifically, variation in identification of prenatal exposure to opioids (PEO), as well as location and level of care for PEO infants, nonpharmacologic treatment, and type of medication utilized (if appropriate), all affect length of stay and the overall cost of care. ${ }^{17}$

This paper examines the demographics and cost of care of PEO in all neonates born at a large southwest Ohio hospital during a 1-year period, with particular attention to identification procedures and care that was offered/received both to the neonates and to their birthing parent.

\section{METHODS}

This is a case-control study of PEO in neonates. After approval by the Wright State University institutional review board, retrospective chart review was conducted of all newborns born between May 1, 2016, and April 30, 2017, as well as the charts of their birthing parent, at a large hospital in southwest Ohio which is home to a Level 3 neonatal intensive care unit (NICU). A diverse research team convened regularly to develop the study. As described below, determining inclusion in the study group proved to be a time-consuming and challenging task and was ultimately determined by team consensus after review of many data points.

Of the 3841 neonates born during the study period, 131 (3.4\%) were identified with PEO. Each of the 131 newborns identified with PEO were matched, based on type of insurance, race/ ethnicity, method of birth delivery, and maternal parity, with a control group of 131 neonates born to women without OUD.

\section{Measures/Outcomes:}

The primary measures included timing of the first, and the total number of, prenatal visits, engagement of the mother in medication-assisted treatment (MAT), length of stay of each newborn in hospital and NICU, and cost of hospitalization.

\section{RESULTS}

\section{Demographics}

Of this sample of neonates, 131 (3.4\%) were born to mothers with OUD. For the entire cohort of 3841 infants born during the study period, $66.5 \%$ were classified as White, $24.0 \%$ were Black, 1.5\% were Asian, and $0.2 \%$ were Native American. In comparison, for the sample of 130 mothers with an OUD, the proportion of White mothers was disproportionately high $(84.4 \%$ of those in the study group), while Blacks (13.4\%) and Asians (0.4\%) were much lower than their representation in the general population.

Similarly, the type of insurance coverage differed significantly for the group of infants with PEO compared to the entire cohort of 3841 neonates. Whereas $93.9 \%$ of the mothers with OUD and their infants received Medicaid/Medicare insurance coverage, only $47.9 \%$ of those in the entire cohort had Medicaid/Medicare insurance and $46.9 \%$ had private insurance.

Of the 262 births in the study (cases and controls), 32 were from first pregnancies. Sixteen of these first-time pregnancies were in the OUD group.

\section{Impact of OUD on Prenatal Care}

Similar to data reported by Clemans-Cope and colleagues, ${ }^{10}$ women with OUD who were pregnant in this study experienced delayed prenatal care and had significantly fewer postpartum visits than women in the control group, $t(250)=2.75, p=.006$. Only 25 (19.2\%) of the 130 women with OUD received MAT with methadone or buprenorphine at any time during the pregnancy. The percentage of women with OUD who were engaged in MAT was even lower for those pregnant for the first time: only 1 of 16 (6.2\%) received MAT.

\section{Length of Hospital (and NICU) Stays}

Compared to the control group, newborns with PEO had longer hospital lengths of stay (LOS) after birth and higher NICU admission rates, corroborating additional data from Clemans-Cope et al. ${ }^{10}$ Babies born to mothers with OUD spent significantly more time in the hospital after birth (mean $=16.9$ days) than those born to mothers without OUD (mean $=5.8$ days), $t(255)=-6.44$, $p<001$. Significantly more neonates in the PEO group spent time in the NICU than the newborns in the control group. Of the 131 infants in the PEO group, 71.4\% went to the NICU, compared to $25.4 \%$ of the 131 newborns in the control group $X^{2}(\mathrm{df}=1$, $n=252)=57.31, p<.001$. Neonates whose birthing parent had OUD spent more than 3 times longer in the NICU, $t(250)=6.16$, $p<.001$, a mean of 14.4 compared to 4.1 days controls.

\section{Financial Burden of PEO}

A lack of prenatal care has been associated with significant increases in maternal and newborn morbidity and cost of care,, 12 which proved to be the case in this study. In aggregate, 90 neonates with PEO were treated in the NICU, leading to aggregate costs of $\$ 1918388$, while 32 newborns in the control group incurred \$623 598 in NICU with charges.

To examine cost differences between neonates with PEO and those without PEO, a more detailed analysis was conducted. Typical 
NICU care for most infants costs between $\$ 1000$ and $\$ 50000$. In our study there were 5 neonates ( 3 in the control group and 2 in the PEO group) whose NICU costs exceeded $\$ 50000$ each. It was discovered that the inordinately high cost for these 5 outliers were, in each case, due to diagnoses unrelated to PEO. Because this study is attempting to determine differences in cost caused by PEO, these 5 outliers were removed from the analysis. After this was done, a significant difference was observed between the NICU costs for PEO and control infants, $t(115)=-2.65, p=.009$. Mean NICU cost per baby in the PEO group was $\$ 19204$ as compared to $\$ 13323$ for controls.

\section{DISCUSSION}

One of the more important findings of this paper was that establishing a diagnosis of maternal OUD and/or PEO in newborns was an enormous undertaking. Without a uniform standard for screening for or documenting substance use in pregnancy, no single component of the medical chart proved to be a fully reliable source. For example, while some have called for universal drug testing, ${ }^{18}$ it is well known that urine testing is not sufficient in and of itself for identification of OUD. However, in our study, urine drug testing was frequently utilized as one of the (and sometimes the only) tool(s) for identifying PEO. Further, it was used without uniformity. For example, of the 130 women found to have OUD, 33 underwent this testing once, 19 twice, 16 three times, and 25 four or more times during the prenatal period. Because of these types of inconsistencies in the medical record, in order to identify infants with PEO, many different, unique searches of both maternal and neonatal records had to be utilized. Searches of maternal records included searching problem lists, admission diagnoses, records of maternal complications, results of urine screens, social history, and medication lists. Likewise, newborn charts were scrubbed for diagnoses, medications, admission to the NICU (and diagnoses at NICU admission), and neonatal abstinence syndrome scores. Ultimately, a manual read of the maternal admission history and physical proved to be 1 of the most informative sources. The final decision for whether or not a newborn and its parent were in the study group was made by a consensus of the entire research team after reviewing all available data points.

In spite of these efforts, we may not have captured all neonates with PEO. As studies have pointed out, traditional screening methods underestimate PEO and allow a significant percentage of persons with OUD who are pregnant or who have just given birth, and their newborns, to go untreated. ${ }^{9}$ Given that the incidence of maternal OUD in our study was only $3.3 \%$, which is less than half the national average, we believe that the incidence of PEO was higher than what we were able to determine, given the lack of consistency in identifying these dyads, and the lack of consistent documentation when OUD or PEO was identified.

Although the data for this study is from the years 2016-2017, it illustrates an ongoing issue both in Ohio and nationally. As discussed in the introduction to this paper, diagnosing OUD in preg- nancy or PEO in neonates continues to be a challenge. In spite of ongoing/updated recommendations from ACOG and other experts, there is no national standard for doing so, nor does such a standard exist in Ohio. A statewide and/or national standardized approach to screening and documentation would significantly enhance the quality of care given to these dyads. For instance, well-established OUD screening tests such as 4Ps, NIDA Quick Screen, and CRAFFT (for women 26 years of age or younger) integrated into the prenatal visits and ultimately accessible in a consistent location in the electronic medical record would provide a much-improved mechanism for early identification of PEO and standardization of care as recommended by ACOG 2021.12 Such standardization would also make data gathering and research more straightforward, which would ultimately lead to further improvements in care for this population.

Another important finding of this paper is that of the 130 pregnant women with OUD, $91 \%$ were on Medicaid or Medicare. Thus, the government bears the lion's share of the cost for caring for women with OUD and their newborns. Cost-containment strategies (teambased care, standardization of nonmedication treatment, and standardization of medical treatment protocols) are all part of the opportunities that have been evaluated in our area and in Ohio at large. Another major cost-containment strategy that is being evaluated nationally is site of care for neonates with PEO. The noninferiority evaluation of rooming-in instead of NICU utilization, as well as offsite neonatal abstinence syndrome treatment facilities for the woman and infant after discharge, provide substantially improved cost without concerns for safety. ${ }^{19,20}$

Local and regional interventional strategies, particularly those focused on identification and treatment of prenatal and postpartum OUD, create an opportunity to reevaluate the outcomes from this study. For example, since the collection of the data in this study, our local region has further developed 2 focused medical homes for pregnant patients with substance use disorders and their families.21,22 Additionally, the Ohio region has standardized the recommended medical home model for this population in the collaborative quality improvement work groups. ${ }^{23}$ Lastly, the region has initiated and further developed a model of care treating neonatal abstinence syndrome in an outpatient setting supporting the postpartum parent and the infant together. ${ }^{24}$

\section{PUBLIC HEALTH IMPLICATIONS}

Whether due to the persistent stigmatization of those with SUD, the threat of engagement with social service agencies, injury to the physician-patient relationship, the relative infancy of addiction medicine, or perhaps the disconnectedness of the physician community from their colleagues and community agencies treating SUDs, the problem of maternal OUD/neonatal PEO and their consequences beg for a systematic, comprehensive, and multidisciplinary approach to screening, diagnosis, and treatment of pregnant women with OUD and PEO in their newborns. Consistent, standardized, respectful sharing of this diagnosis, as well as of treat- 
ment interventions, in the medical record would additionally greatly enhance care for these patients and would, hopefully, improve outcomes for all involved. In addition, this study highlights the need to reevaluate the diagnostic inclusion and accuracy, teambased care, length of stay and cost of care with this high-risk population as well as the updated modalities since this data collection.

\section{REFERENCES}

1. Ohio Department of Health. 2019 Ohio Drug Overdose Data: General Findings. Accessed November 2021.

https://odh.ohio.gov/wps/wcm/connect/gov/0a7bdcd9-b8d5-4193-a1afe711be4ef541/2019_OhioDrugOverdoseReport_Final_11.06.20.pdf? MOD $=$ AJPERES\&CONVERT_TO $=$ url\&CACHEID $=$ ROOTWORKSPACE.Z18_M1HGGI K0N0J000Q09DDDDM3000-0a7bdcd9-b8d5-4193-a1af-e711be4ef541-nmv3qSt

2. Ohio Department of Health. 2018 Ohio Drug Overdose Data: General Findings. Accessed November 2021.

https://odh.ohio.gov/wps/wcm/connect/gov/d9ee6d3b-bf62-4b4f-8978d7cfcd11348f/2018_OhioDrugOverdoseReport.pdf? MOD $=$ AJPERES\&CONVERT_TO $=$ url\&CACHEID $=$ ROOTWORKSPACE.Z18_M1HGGI K0N0J000Q09DDDDM3000-d9ee6d3b-bf62-4b4f-8978-d7cfcd11348f$\mathrm{mXhFqNO}$

3. Ohio Department of Health. 2017 Ohio Drug Overdose Data: General Findings. Accessed November 2021.

https://odh.ohio.gov/wps/wcm/connect/gov/5deb684e-4667-4836-862bcb5eb59acbd3/2017_OhioDrugOverdoseReport.pdf?

MOD $=$ AJPERES\&CONVERT_TO $=$ url\&CACHEID $=$ ROOTWORKSPACE.Z18_M1HGGI K0N0J000Q09DDDDM3000-5deb684e-4667-4836-862b-cb5eb59acbd3mJWbwTP

4. Ohio Department of Health. 2016 Ohio Drug Overdose Data: General Findings. Accessed November 2021.

https://odh.ohio.gov/wps/wcm/connect/gov/d174de32-5703-4ef2-ad0c804f9aa5f0de/2016_OhioDrug0verdoseReport.pdf? MOD=AJPERES\&CONVERT_TO $=$ url\&CACHEID =ROOTWORKSPACE.Z18_M1HGGI K0N0J000Q09DDDDM3000-d174de32-5703-4ef2-ad0c-804f9aa5f0denmuj8mw

5. Ohio Department of Health. 2015 Ohio Drug Overdose Data: General Findings. Accessed November 2021.

https://odh.ohio.gov/wps/wcm/connect/gov/99fa7461-eaac-4cea-aa7db29cb13c4127/2015_OhioDrugOverdoseReport.pdf? MOD $=$ AJPERES\&CONVERT_TO $=$ url\&CACHEID =ROOTWORKSPACE.Z18_M1HGGI K0N0J000Q09DDDDM3000-99fa7461-eaac-4cea-aa7d-b29cb13c4127-nmuJoie

6. Ohio Department of Health. 2014 Ohio Drug Overdose Data: General Findings. Accessed November 2021.

https://odh.ohio.gov/wps/wcm/connect/gov/2bcaae73-362a-4215-879ba79fa0117d84/2014_OhioDrugOverdoseReport.pdf? MOD $=$ AJPERES\&CONVERT_TO $=$ url\&CACHEID $=$ ROOTWORKSPACE.Z18_M1HGG K0N0J000Q09DDDDM3000-2bcaae73-362a-4215-879b-a79fa0117d84nmuJvmy

7. Haight SC, Ko JY, Tong VT, Bohm MK, Callaghan WM. Opioid use disorder documented at delivery hospitalization - United States, 19992014. MMWR Morb Mortal Wkly Rep. 2018;67(31):845-849. https://doi.org/10.15585/mmwr.mm6731a1

8. Hirai AH, Ko JY, Owens PL, Stocks C, Patrick SW. Neonatal abstinence syndrome and maternal opioid-related diagnoses in the US, 20102017. JAMA. 2021 Jan 12;325(2):146-155. https://doi.org/10.1001/jama.2020.24991

9. Rausgaard NLK, Ibsen IO, Jørgensen JS, Lamont RF, Ravn P. Management and monitoring of opioid use in pregnancy. Acta Obstet Gynecol Scand. 2020;99(1):7-15.

https://doi.org/10.1111/aogs.13677
10. Clemans-Cope L, Lynch V, Howell E, et al. Pregnant women with opioid use disorder and their infants in three state Medicaid programs in 2013-2016. Drug Alcohol Depend. 2019;195:156-163. https://doi.org/10.1016/j.drugalcdep.2018.12.005

11. Nagarajan MK, Goodman D. Not just substance use: the critical gap in nutritional interventions for pregnant women with opioid use disorders. Public Health. 2020;180:114-116. https://doi.org/10.1016/j.puhe.2019.10.025

12. American College of Obstetrics and Gynecology. Opioid Use and Opioid Use Disorder in Pregnancy. Committee Opinion number 711; Aug 2017. Reaffirmed Oct 2021.

https://www.acog.org/clinical/clinical-guidance/committee-opinion/ articles/2017/08/opioid-use-and-opioid-use-disorder-in-pregnancy

13. Barbose- Leiker C, Campbell A, McHugh K, Guille C, Greenfield S. Opioid use disorder in women and the implications for treatment. Psych Res Clin Pract. 2020; 3(1): 3-11.

https://doi.org/10.1176/appi.prcp.20190051

14. Smid M, Saitz R. Postpartum treatment of individuals with opioid use disorder: maternal risk and need for evidence do not end when pregnancy ends. J Addict Med. 2021;15(4):267-268. https://doi.org/10.1097/ADM.0000000000000878

15. American College of Obstetrics and Gynecology. Opioid Use and Opioid Use Disorder in Pregnancy. Committee Opinion number 524; May 2012. Replaced Aug 2017.

16. Ohio Department of Health. 2017 Ohio Pregnancy Assessment Survey (OPAS): Key Findings Summary. Accessed November 2021.

http://odh.ohio.gov/wps/portal/gov/odh/know-our-programs/ohio-pregnancy -assessment-survey-opas/resources/2017-opas-key-findings-summary

17. Walsh M, Crowley M, Wexelblatt S, Ford S, et al. Ohio perinatal quality collaborative improves care of neonatal narcotic abstinence syndrome. Pediatrics, 2018; 141(4): e20170900. https://doi.org/10.1542/peds.2017-0900

18. Wexelblatt SL, Ward LP, Torok K, Tisdale E, Meinzen-Derr JK, Greenberg JM. Universal maternal drug testing in a high-prevalence region of prescription opiate abuse. J Pediatr. 2015;166(3):582-586. https://doi.org/10.1016/j.jpeds.2014.10.004

19. Whalen B, Holmes A, Blythe S. Models of care for neonatal abstinence syndrome: what works? Semin Fetal Neonatal Med. 2019 Apr;24 (2):121-132. https://doi.org/10.1016/j.siny.2019.01.004

20. MacMillan K, Rendon C, Verma K, Riblet N, Washer DB, Holmes AV. Association of rooming-in with outcomes for neonatal abstinence syndrome: a systematic review and meta-analysis. JAMA Pediatr. 2018;172(4):345-351. https://doi.org/10.1001/jamapediatrics.2017.5195

21. Soin Family Practice Center Kettering Health Medical Group. Accessed November 2021. www.ketteringphysiciannetwork.org/practiceservices.cfm? $\mathrm{p}=184$

22. Promise to Hope. Accessed November 2021. https://www.mvhfoundation.org/programs-events/promise-to-hope/

23. Ohio Perinatal Quality Collaborative. Maternal Opiate Medical Supports Plus (MOMS+) Project. Accessed November 2021. www.opqc.net/maternal-opiate

24. Brigids Path Compassion. Care. Guidance. Services and general information. Accessed November 2021. https://brigidspath.org/ 